\title{
Analysis of the long-term stability of an ancient room and abandoned pillar mine-Impact of the water level
}

\author{
F.Vinkler \\ INERIS, Institute National de l'Environnement Industriel et des Risques, Verneuil-en-Halatte, France \\ J.P.Piguet \\ LAEGO, Laboratoire Environnement Géomécanique et Ouvrages, Nancy, France
}

\begin{abstract}
The recent mine water level rise in the iron mines of Lorraine (France), due to their abandon, was followed by several subsidence events. FLAC-2D has been used to analyze the stability of a former twolevel room and pillar mine, in order to predict the extent of the failure zone, depending on mechanic property and geometry modalities (bad superimposition of the pillars in the two seams particularly). The model successively simulates the water level rise then the long-term strength reduction, which is partially due to the rock resaturation. The long-term criteria are based on the point of crack initiation determined via laboratory tests. The long-term stability diagnostic expressed by the experts is confirmed in whichever geometrical configuration of the exploitation, and whatever mechanical properties are used. Nevertheless more precise characterizations of the hydromechanical behavior should be planned for more critical sites to improve the evaluation of the mine failure hazard.
\end{abstract}

\section{INTRODUCTION}

During the last three years, the surface of the iron basin in Lorraine (France) subsided straight above several recently flooded mines, after the water pumping ceased. Studies were therefore launched to examine the role the mine water rise plays in these instabilities. Several cities located straight above abandoned mine areas with characteristics similar to that of already subsided sites have initiated studies in order to locate, evaluate, and possibly prevent the hazards.

This article focuses on an ancient mine, which is $100 \mathrm{~m}$ deep. and has been exploited on two levels separated by a $5 \mathrm{~m}$ thick intercalary layer. The data proceeding from three boreholes allowed mechanical characterizations. Based on the analysis of the geometry and of these characterizations, experts located the possible unstable areas, and advised of preventive actions. They do not conclude to any major long-term hazard, but emphasize on further research to be made concerning the hydromechanical behavior of the rocks, and the preventive monitoring of microseismical events precursory to a possible subsidence.

This numerical study has several goals. First it aims at confirming the long-term stability diagnostic expressed by the experts, and predicting the short and long-term failure zones. Then it seeks to evaluate the respective impact on failure. on the one hand of the long-term strength reduction, on the other hand of stress variations during the water level rise. Finally several instability scenarios, considered as possible by the experts, have been studied: locally below average mechanical properties or potentially dangerous geometry (especially bad superimposition of the pillars in the two seams).

\section{HYDROMECHANICAL INTERACTIONS N THE MINES}

The hydromechanical interactions around undermined areas are characterized by three phenomena:

- local permeability changes, as a consequence of excavation-induced fracturing and aperture changes related to the stress variation;

- hydraulic pressure changes, related to the water table decline during exploitation, then rise after the pumping ceases;

- mechanical properties change (particularly compression and tension strengths) as a function of the saturation degree.

\subsection{Stress variations related to the water level rise}

Terzaghi's classical law (valid in porous media) states that the pore pressure increase results in a reduction of the effective stress by the same amount. thus in a rise of the local failure risks.

In fractured rock masses with a highly impermeable matrix, the pore pressure increase has the effect 


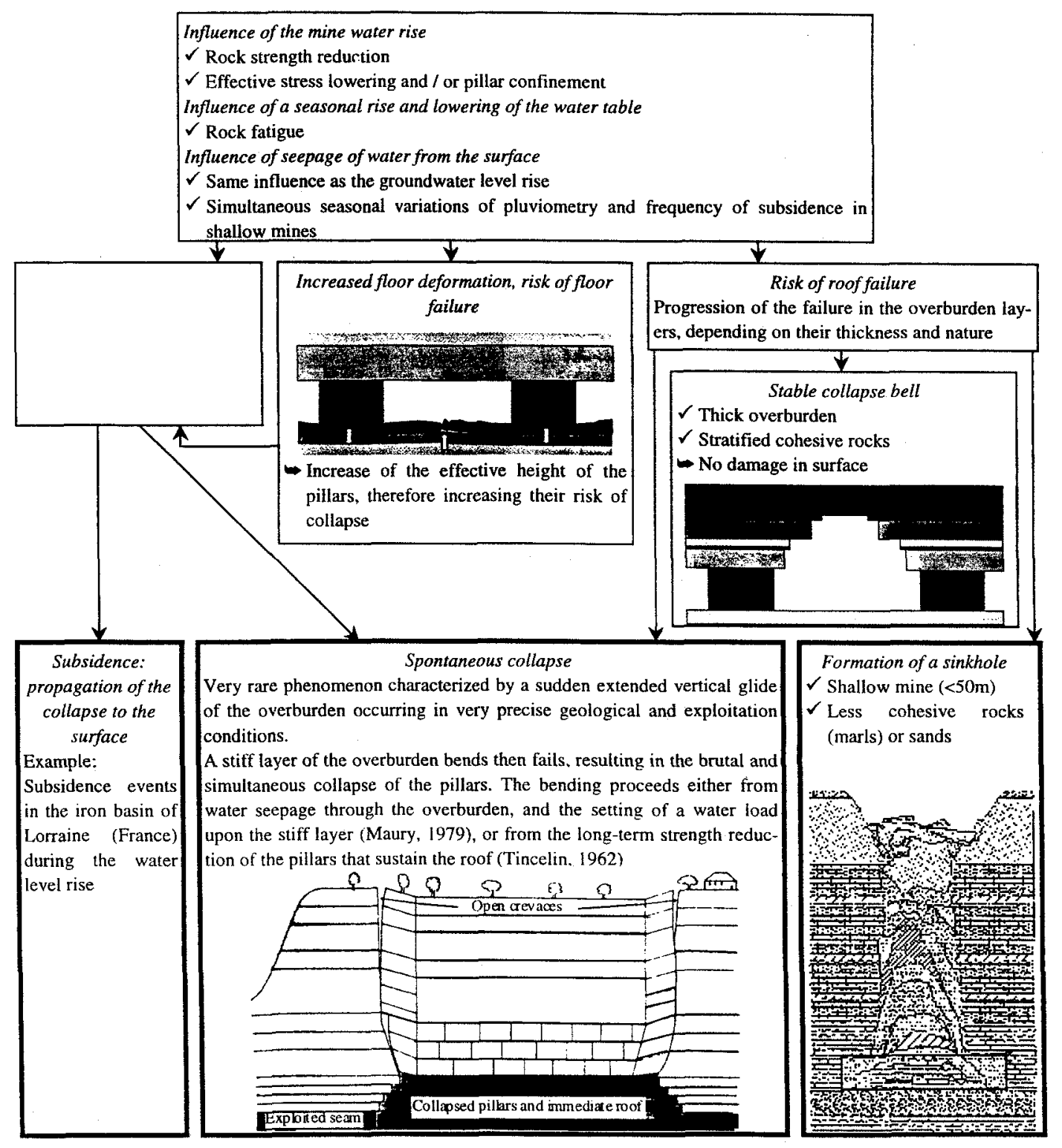

Figure 2. Room and pillar mines. Impact of a change in their hydraulic environment on their stability

For each rock type, a series of physical and mechanical tests was undertaken, which gave the average values (table 1) of the properties, as well as their variability. Note that the testing did not allow the monitoring of stresses and strains after peak-strength was reached.

The intercalary marls may constitute the weakest point of the mine, considering their clay content, particular position, and the variability of their prop- erties. Despite the presence of clay, the tests do not show any creep-related differed deformation. On the other hand. they develop a swelling pressure up to $0.5 \mathrm{MPa}$, which most certainly proceeds from the chemical reaction of pyrite. Furthermore the mechanical properties do not differ from those of the orher facies. The experts therefore estimated that the hazards usually associated with the intercalary maris in the iron mines seem unlikely here. 


\subsection{Mechanical properties}

Table 1. Average properties of the facies

\begin{tabular}{|c|c|c|c|c|c|}
\hline \multicolumn{6}{|c|}{ Hydraulic properties } \\
\hline Porosity $n$ & 0.15 & 0.30 & 0.20 & 0.30 & 0.15 \\
\hline Permeability $\left(10^{-18} \mathrm{~m}^{2}\right)$ & 1 & 5 & 4 & 16 & 6 \\
\hline \multicolumn{6}{|c|}{ Mechanical properties in elasticity } \\
\hline $\mathrm{E}(\mathrm{MPa})$ & 6900 & 12000 & 8200 & 10200 & 6700 \\
\hline$v$ & 0.15 & 0.30 & 0.15 & 0.30 & 0.20 \\
\hline \multicolumn{6}{|c|}{ Short-term strength properties } \\
\hline $\mathrm{R}_{c}(\mathrm{MPa})$ & 17.0 & 29.0 & 20.0 & 25.0 & 20.2 \\
\hline$R_{\mathrm{t} S T}(\mathrm{MPa})$ & 1.2 & 2.6 & 2.5 & 1.5 & 2.5 \\
\hline $\mathrm{C}_{\mathrm{sT}}(\mathrm{MPa})$ & 2.6 & 5.0 & 3.8 & 3.4 & 4.6 \\
\hline $\operatorname{PST}_{\mathrm{ST}}(\mathrm{MPa})$ & 49 & 45 & 36 & 55 & 41 \\
\hline \multicolumn{6}{|c|}{ Long-term strength properties } \\
\hline$R_{E}=R_{c, L T}(\mathrm{MPa})$ & 9.2 & 13.9 & 13.0 & 11.6 & 13.9 \\
\hline $\mathbb{R}_{\mathbf{L}, \mathbf{L T}}(\mathrm{MPa})$ & 0.6 & 1.2 & 1.6 & 0.7 & 1.7 \\
\hline$c_{\mathrm{LT}}(\mathrm{MPa})$ & 1.4 & 2.4 & 2.5 & 1.6 & 3.2 \\
\hline$\varphi_{L T}(\mathrm{MPa})$ & 39 & 35 & 26 & 45 & 31 \\
\hline
\end{tabular}

$\begin{array}{ll}\text { Properties: } & \\ \text { "Red" seamr } & \\ \text { "Grey" seam } & \text { Micaceous marls } \\ \text { Roof marls }\end{array}$

Parameters for the long-term failure criterion:

$$
\begin{aligned}
& c_{\mathrm{LT}}=c_{S T} \frac{R_{E}}{R_{c}} \\
& R_{\mathrm{t}, \mathrm{LT}}=R_{\mathrm{t}, \mathrm{ST}} \frac{\mathrm{R}_{\mathrm{E}}}{\mathrm{R}_{\mathrm{c}}} \\
& \varphi_{\mathrm{LT}}=\varphi_{\mathrm{ST}}-10^{\circ}
\end{aligned}
$$

where: $R_{c}, R_{E}, R_{t}, c(P a)$ and $\varphi$ respectively refer to the peak strength, the elastic limit, the tensile strength, the cohesion and the friction angle of the rock

sr and ${ }_{\mathrm{LT}}$ refer to short and long-term properties

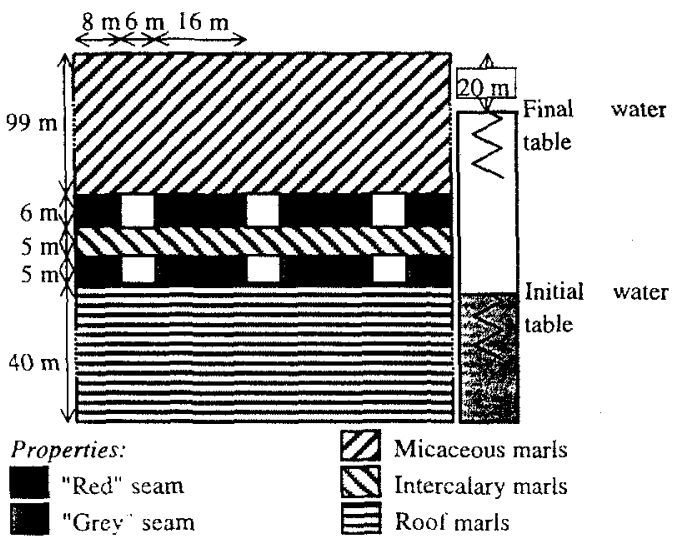

Figure 3. Basic geometry of the model.

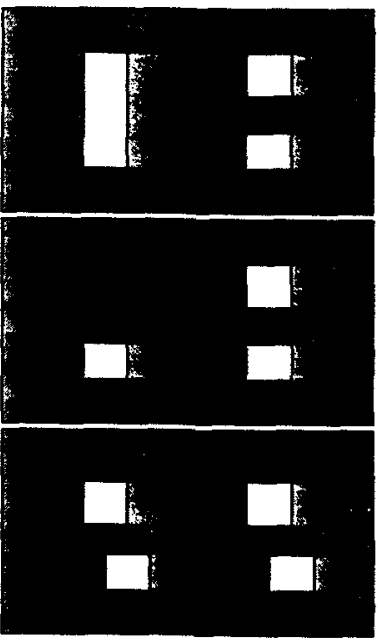

Collapse of the intercalary layer between two rooms

Transition zone between a two-level and a one-level exploitation

Superimposition shift $d_{p}$ of the pillars in the two exploited seams; reduced thickness $e_{i}$ of the intercalary layer

Figure 4. Alternative geometry.

In order to account for the dehumidification creep, fatigue... of the rocks, long-term failure criteria must be devised. From the results of Wiid (1970), it appears that, for wet dolerite, the point of crack initiation ( $R_{E}$, also elastic limit), is a better measure of the ultimate strength.

The pre-failure behavior in the different mechanical models used is always linear elasticity. The failure criterion is also always Mohr-Coulomb's.

The first option set gave the choice between including the average properties coming from the tests, or decreasing them by one standard deviation, particularly to take into account the spatial variability of the data.

To simulate the post-failure behavior of the rocks, unknown since not monitored during the tests, two options were tested:

- strain-softening (Fig. 5). The parameters were estimated according to the bibliography. Tests carried out in our laboratory and Bieniawski (1972) show a ratio between residual and peak-cohesion varying from 0.25 (sandstone, gabbro) to 0.7 (coal). We retained an intermediate value, 0.4 The friction angle decreases by $5^{\circ}$.

- perfect plasticity.

\subsection{Choice of a numerical model}

Several reasons explain why FLAC-2D was chosen to run the models:

- a porous medium model is fit for little fractured rocks;

- the use of the effective stress to simulate hydromechanical coupling is in adequacy with the be havior of the rocks: 


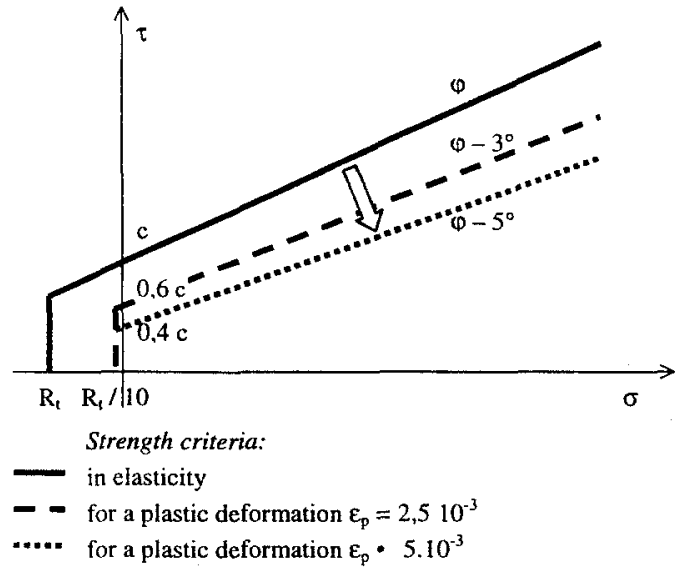

Figure 5. Strain-softening model.

- it is possible to experiment several mechanical and geometrical models, and to compare them on the basis of the extent of the failure zone.

It was decided to use a two-dimensional model to save time and improve the grid precision. However, the rooms parallel to the model brought about a problem. It was solved by increasing the density of the gridpoints just above the pillars, so that the stress in the pillars is equal to that calculated by the "tributary area" model.

The comparisons between different models are made in terms of failure zone extension. As any plastic area was considered as in failure, the failure zones were identified when plotting the plastic points.

\subsection{Calculations stages}

FLAC-2D was chosen to run the models, as it is adapted to the modeling of porous media with few fractures. The command CONFIG GW was used to explicitly simulate the water table rise. Rocks were given either strain-softening or Mohr-Coulomb plasticity model, depending on the assumptions.

The calculations has been divided into three stages, which can also be subdivided:

- initial state after exploitation. Rocks have shortterm mechanical behavior. The water table is $1 \mathrm{~m}$ below the mine wall. The saturation degree of the rocks above water table is set to $95 \%$ in order to account for the near-saturation of the rocks due to capillarity (Fig. 1);

- adoption of long-term failure criteria:

- progressive rise of the water table. The final level is set to $20 \mathrm{~m}$ below the surface (regional level). The mine water rise causes effective stress lowering in all flooded rocks, but also a marginal ad- ditional load brought about by water entering into the rock masses (the saturation degree increases from $95 \%$ to $100 \%$ in the resaturated rocks).

\section{MODEL RESULTS}

\subsection{Basic case}

The basic case features the basic geometry (Fig. 3) and a mechanical behavior based on average properties and strain softening after rock failure (Fig. 4). Figure 6 shows the evolution of the failure zone during the calculation stages.

A failure zone progressively develops at the roof of the upper rooms. The central gridpoints undergo tensile failure while the others undergo shear failure. The wide extent of the failure zone proceeds from the weak cohesion and tensile strength of the micaceous marls and from the pore pressure increase. The plastic deformation can reach several percent, thus lowering the failure criteria (impact of the strain softening law adopted) and furthering the failure zone extent.

The grey seam progressively fails in shear, while the red seam much less. as a consequence of more favorable long-term strength. In this geometry, the intercalary marls are fairly stable.

The vertical stress in the pillars (Fig. 7) is conform to that calculated by the "tributary area" model: they vary on the center of the pillar from -3.03 to 3.29 MPa (compressive stress are negative). Shear stress develops at the angles of the rooms, as well as tensile stress at the roofs of the upper room. The intercalary layer, between the rooms, undergoes weak horizontal and vertical stress. The principal stress is horizontal.

As an effect of the pore pressure increase, most gridpoints in the marlic facies have tensile minor principal stress at the final stage of the calculation. the stress varying from 0.2 to $0.5 \mathrm{MPa}$, which stays below the tensile strength, ranging from 0.6 to $1.7 \mathrm{MPa}$ depending on the facies but are still considerable.

4.2 Respective contributions to the extension of the failure zone of the strength reduction and the pore pressure increase

Two models have been run. each of them excluding either the strength reduction or the pore pressure increase. In both cases the induced failure zones are fairly similar and have a very limited extension. None of them. taken alone, can trigger more than a very minor local failure. Only the conjunction of both factors can lead to an extended failure zone, hence the need of a good estimation of the long-term strengths of the rocks. 


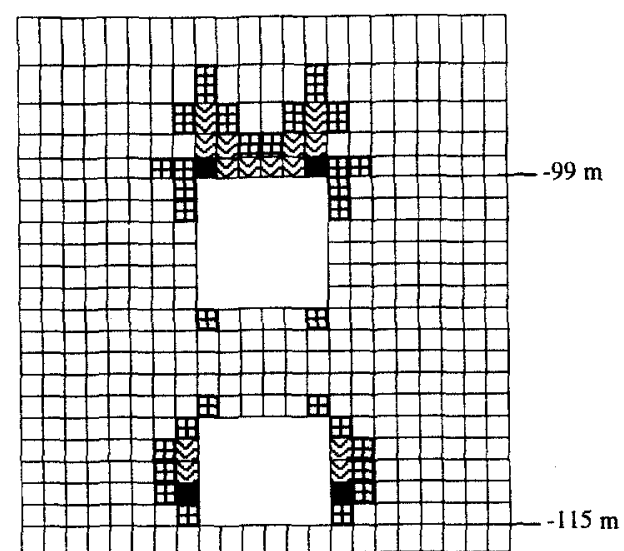

Contributions to the extension of the failure zone:

Introduction of the long-term properties

Water table set to $-50 \mathrm{~m}$

田 Water table set to $-20 \mathrm{~m}$

Figure 6. Evolution of the failure zone during the calculation stages - Basic case.

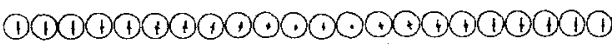

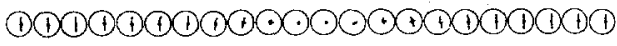

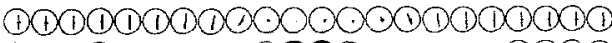

(1)DD(1) ; : $1-9009-2+110000$
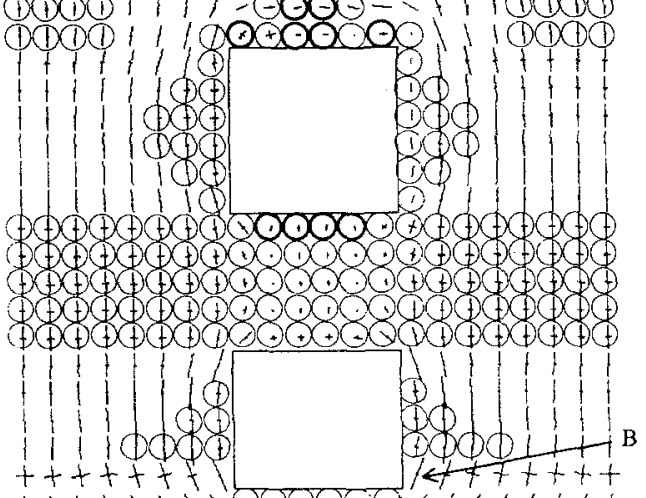

$+x+x+x+800 \times 00 \times \times \times x+x+1$

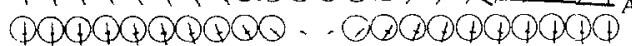

Minor effective stress in tension

Minor and major effective stresses in tension

Scale: $=5 \mathrm{MPa}$

Example: The effective principal stress at gridpoint $\mathrm{A}$ are $3.73 \mathrm{MPa}$ and $-2.29 \mathrm{MPa}$

Maximum effective stress: $-5.06 \mathrm{MPa}$ (gridpoint B)

Figure 7. Effective stress after introduction of the long-term strengths and pore pressure increase - Bastc case.

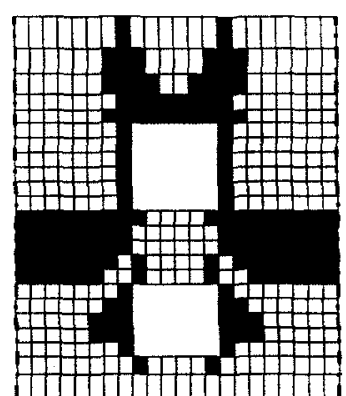

(a)

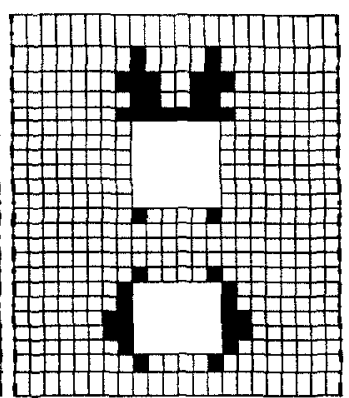

(b)
- post-rupture

strain softening

behavior: post-rupture behavior: perfect plasticity

- average properties

Figure 8. Failure zones after introduction of the long-term strengths and pore pressure increase - Basic geometry, different mechanical behaviors

Furthermore, observation of the induced plastic deformations in this geometrical configuration and others shows that the strength reduction has a more preponderant impact on failure development than the pore pressure increase.

\subsection{Reduction by one standard deviation of the mechanical properties}

Under these conditions, the Mohr circles representative of the stresses in the intercalary maris in the pillars systematically intersect the failure criterion (Fig. 8a). On the other hand, the failure zones around the rooms only increase a little compared to the basic case. But should these conditions be met, the scale of the failure zone would be sufficient to bring about a global collapse.

Nonetheless the persistence, on the scale of the model $(22 \mathrm{~m})$, of well-below average properties has been denied by the tests. since specimens collected very near from one another often displayed a great variability in their characteristics. This model only shows that intercalary marl areas with locally weak properties may ultimately collapse. A model where the intercalary marls had stochastically distributed properties showed that these local failures do not result in global instability. Another model was also built, with properties reduced by one standard deviation in one pillar and stochastically distributed properties in the others. The calculations showed that the collapse of the first pillar did not have any consequence on the stability of the adjacent ones. The only result would be a local instability. 


\subsection{Post-failure behavior: perfect plasticity}

The introduction of perfect plasticity as post-failure behavior involves a notable reduction of the failure zone, particularly at the roof of the upper room (Fig. 8b). The huge reduction of the tensile strength in the strain softening law actually contributes mostly to the extension of this failure zone. As this feature is legitimate, it is therefore more coherent and safer to use the strain softening law, even with estimated parameters. Appropriate tests are planned later to provide for precise characterizations of the post-failure rock behaviors.

\subsection{Collapse of the intercalary layer between two rooms}

This geometry (Fig. 4a) did not prove to be dangerous. It causes a minor extension of the failure zone in the intercalary marls, and very limited consequences on the failure zones around the adjacent rooms.

Contrary to what the experts feared, the intercalary marls are stiff enough not to be squeezed between the two iron seams, after the intercalary layer between two rooms has collapsed. This event, should it occur (as the calculations made above do not show it as granted, it could only be an isolated event), would not lead to any consequence in terms of overall stability.

\subsection{Transition zone between a two-level and a one- level exploitation}

The failure zones around the rooms are very little affected in this configuration (Fig. 4b). In effect, in the transition zone the stresses range between those calculated in a two-level and a one-level exploitation. Consequently any locally specific increase of the failure zones is impossible in this configuration.

\subsection{Superimposition shift of the pillars in the two exploited levels}

All the observations have shown that the instability hazards increase with the superimposition drift (Fig. 4c). It is therefore useful to study the impact of different values of the drift on the overall stability, and to deduce the maximum admissible drift.

The failure zone around the rooms greatly increases with the superimposition drift. Not very different to that in the basic case for a $1 \mathrm{~m}$ or $2 \mathrm{~m}$ drift (Fig. 9), a dangerous situation develops for a $3 \mathrm{~m}$ drift.

The intercalary layer begins then to undergo failures in traction, likely to result in its collapse. Note however that FLAC cannot conclude whether the "failure zone" information means development of a fracture network or the utter collapse of the zone in

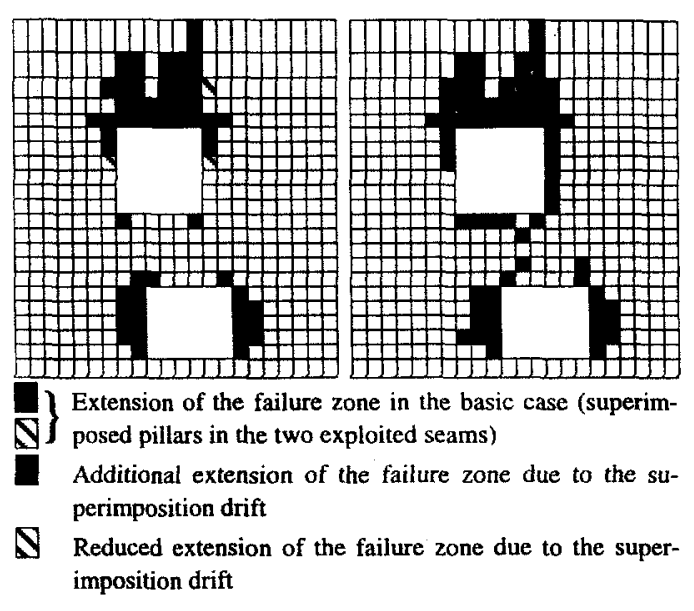

Figure 9. Extension of the failure zone $-2 \mathrm{~m}$ and $3 \mathrm{~m}$ superimposition drift of the pillars in the two exploited seams.

question. Nevertheless in this present case the failure mode (tension) of the intercalary marls means a final collapse is more likely. Moreover this conclusion promotes a safer analysis.

\section{$4.83 \mathrm{~m}$ Superimposition drift and depth of the intercalary layer reduced to $4 \mathrm{~m}$}

This even more unfavorable configuration has been used to analyze the consequences of a collapse of the intercalary layer.

The collapse of a unique intercalary layer results in a significant extension of the failure zone in the surrounding pillars (Fig. 10a). Moreover, the failure zones around the adjacent rooms increases slightly, which may also trigger the collapse of their already disturbed intercalary layers. If however the collapse remains an isolated event, the induced failure zone cannot endanger the overall stability.

The long-term global collapse of all the intercalary layers between the rooms represents a very pessimistic but plausible assumption. These events could occur as a chain reaction but also progressively and individually. Even in these extreme conditions, the pillars remain stable, despite an increase in the induced failure zone.

\subsection{Conclusions on this case}

The different calculations allowed locating the weak points in the mine. These are first the grey seam and the micaceous maris. The weak longterm tension strength assigned to the micaceous marls leads to the formation of a tension failure zone at the roof of the upper rooms, which can be seen as the initiation of a sinkhole. As noted before- 


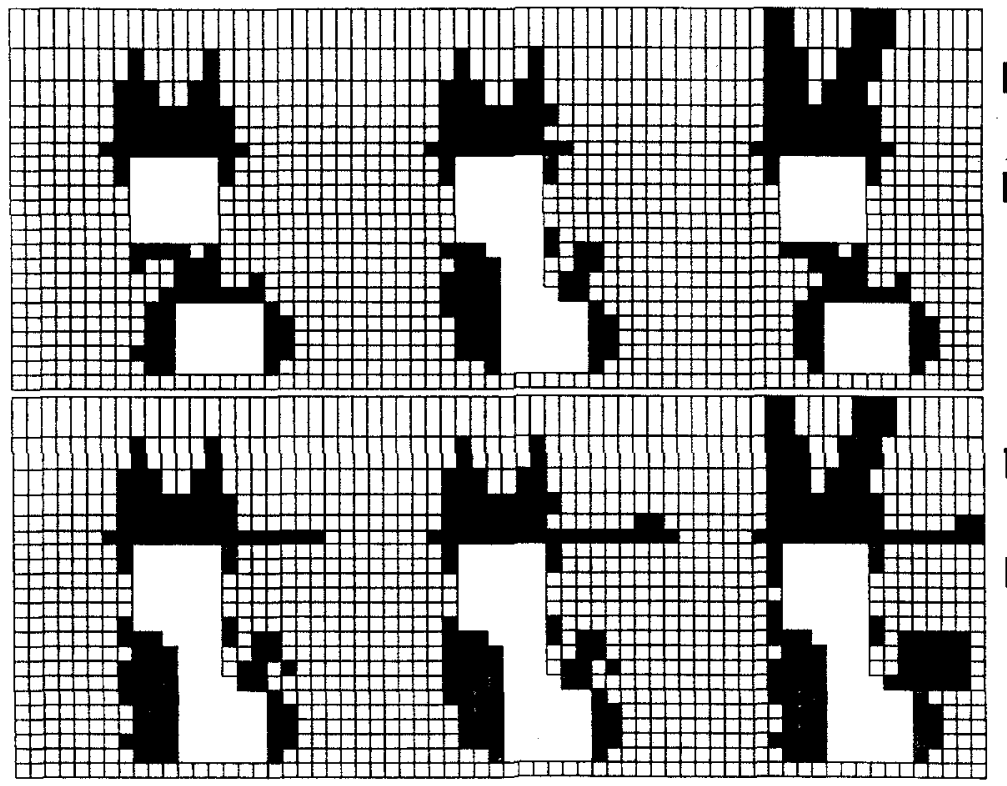

a) Contributions to the extension of the failure zone

of the introduction of long-term properties then of the pore pressure increase

of the collapse of the intercalary layer between two rooms

Figure 10. Influence on the failure zone of the collapse of an intercalary layer between two rooms - 3-m superimposition drift of the rooms in the two exploited seams, depth of the intercalary layer reduced to $4 \mathbf{m}$.

hand, FLAC is not well adapted to the analysis of the formation of sinkholes through roof failure. But no sinkholes has ever been known to have reached the surface from $100 \mathrm{~m}$ (Piguet, 1998), so this scenario would be highly improbable.

The intercalary marls represent the other weak point. The areas with well below average strength may locally fail at long-term as a mere consequence of the state of stress in the pillars, but without consequence on the overall stability.

The state of stress that develops in the intercalary layer between two rooms can lead it to collapse if locally the pillars in the two exploited seams are not exactly superimposed, and the drift exceeds $3 \mathrm{~m}$. However even if this event occurs between several adjacent rooms, the global stability is not affected.

To sum up, in the studied mine failure zones should develop at long term, particularly in the roof of the upper rooms and in the pillars of the lower rooms. The extension of the failure zones varies, depending on the geometric configuration of the mine. and if the mechanical properties locally fall below average. In some extreme configurations, the intercalary layer between two rooms collapses. But the overall stability is never affected.

\section{GENERAL CONCLUSION}

The mine water rise in the ancient room and aban doned pillar mines brings about two phenomena un- favorable to their long-term stability : the pore pressure increase and the strength reduction of the rocks, to which the resaturation, the fatigue, the creep and/or chemical reactions contribute.

The numerical analysis allowed locating the weakness zones in the rock masses and the foreseeable failure mechanisms involved. It also contributed to test easily alternative geometries and mechanical properties. The use of a two-dimensional model led to moderate calculation times in each configuration (about $1 \mathrm{~h}$ ).

The choice of mechanical properties and above all the long-term strength reduction have been shown to have a great influence on the extension of the failure zones. In the present case, no instability can be foreseen in whichever geometrical configuration, and whatever mechanical properties are used. Still in more critical cases a precise characterization of the long-term properties would be necessary, in order to properly evaluate the instability hazards. The emphasis should be put on the determination by specific tests of the real long-term properties, and a fair knowledge of their spatial variability.

\section{REFERENCES}

Bieniawski, Z. T. 1972. Propagation of brittle fracture in rock Proc. $10^{\text {th }}$ Symp on Rock Mech. (AIME) 409-427

Hunt, D. J., Reddish, D. J. 1997. The stability implications of groundwater recharge upon shallow, abandoned mine- 
workings in the UK. In Marinos, Koukis, Tsiambos \& Stoumaras (eds), Engng. Geol. and the Env.: 2425-2430. Rotterdam: Balkema

Maury, V. 1979. Effondrements spontanés - Synthèse d'observations et possibilité de mécanisme initiateur par mise en charge hydraulique. Industrie Minérale. Octobre 1979: 511 522

Piguet, J. P. 1998. Affaissements et déformations au-dessus des exploitations minières: mécanismes, conséquences et facteurs influents. Exposé à la Conférence mondiale sur le développement durable des anciens pays charbonniers. Lille, mars 1997

Tincelin, E., Sinou, P. 1962. Effondrements brutaux et généralisés, coup de toit. Revue de l'Industrie Minérale

Vandenbeusch, M., Wojtkowiak, F. 1992. La prise en compte de l'eau et la prévision des exhaures en mines et carrières. Mines et Carrières, Industrie Minérale. Février 1992: 34 41

Van Eeckhout, E. M. 1976. The Mechanisms of Strength Reduction due to Moisture in Coal Mine Shales. Int. J. Rock Mech. Min. Sci. \& Geomech. Abstr. 13: 61-67

Vinkler, F. 1999. Interaction hydromécaniques dans les massifs rocheux - De l'enfouissement des déchets radioactifs à la remontée des eaux dans les mines abandonnées. Mémoire de thèse, INPL, Nancy

Watelet, J.-M. 1996. Méthode d'analyse et diagnostic des conditions de stabilité des carrières souterraines, Mémoire de Diplôme d'Ingénieur ICAM. Conservatoire National des Arts et Métiers, Paris 